\title{
Commentary: DAMPen ischemia-reperfusion injury?
}

\author{
Richa Dhawan, MD, MPH, and Mark A. Chaney, MD
}

\author{
From the Department of Anesthesia and Critical Care, University of Chicago Medical Center, Chicago, Ill. \\ Disclosures: Authors have nothing to disclose with regard to commercial support. \\ Received for publication Dec 18, 2018; accepted for publication Dec 19, 2018; available ahead of print Jan 23, \\ 2019. \\ Address for reprints: Richa Dhawan, MD, MPH, Clinical Associate, Department of Anesthesia and Critical Care, \\ University of Chicago Medical Center, 5841 S Maryland Ave, MC 4028, Chicago, IL 60637 (E-mail: \\ rdhawan@dacc.uchicago.edu). \\ J Thorac Cardiovasc Surg 2019;158:791 \\ $0022-5223 / \$ 36.00$ \\ Copyright (C) 2018 by The American Association for Thoracic Surgery \\ https://doi.org/10.1016/j.jtcvs.2018.12.070
}

Ischemia-reperfusion (IR) injuries after cardiac transplantation remain problematic and increase morbidity and mortality. Mechanisms are complex, and although not yet fully understood they likely involve reintroduction of oxygen and nutrients during reperfusion, leading to myocardial cell death through several mechanisms involving excessive oxidative stress. Damage-associated molecular patterns (DAMPs) appear, which influence IR injuries through several different mechanisms. Several in vitro studies have suggested potential cardioprotective effects of P2Y purinoceptor $11(\mathrm{P} 2 \mathrm{Y} 11)$ receptor $(\mathrm{P} 2 \mathrm{Y} 11 \mathrm{R})$ stimulation during myocardial infarction. In this issue of the Journal, Bourguignon and colleagues, ${ }^{1}$ a group of investigators from France, reveal that such stimulation may be beneficial during cardiac transplantation in a murine model.

The study consisted of two parts. Their in vitro rat model revealed that a P2Y11R agonist increased cell viability after IR, whereas a P2Y11R antagonist abolished this effect. Their in vivo mouse model (104 murine transplantations) revealed that recipients receiving a P2Y11R agonist exhibited improved allograft survival and decreased severity of rejection lesions.

Currently, the only $\mathrm{P} 2 \mathrm{Y}$ receptor subtype used in drug therapy is P2Y purinoceptor12. There are several P2Y subtypes recognized as being involved in cystic fibrosis, obstructive airway diseases, inflammatory bowel disease, and leukemia. ${ }^{2}$ Because of a lack of homologous gene sequence in mice, research is limited with P2Y11. The use of a murine model in this study is controversial, and Bourguignon and colleagues ${ }^{1}$ address this study limitation. They used several methodologic steps, such as Western blot and agonist-antagonist pairs, to identify effects that they state are the direct result of P2Y11 receptor expression. Dreisig and colleagues, ${ }^{3}$ however, recommend the use of tissue from nonmurine species, because P2Y11 agonists and antagonists have the potential to be nonspecific in mice. It is therefore possible that mediation of the ischemia observed in the study of Bourguignon and colleagues ${ }^{1}$ is due to effects from other receptors. The results from this study nonetheless warrant further investigation into the signaling pathway from receptor activation to tissue protection. Potential alternate avenues for studying the

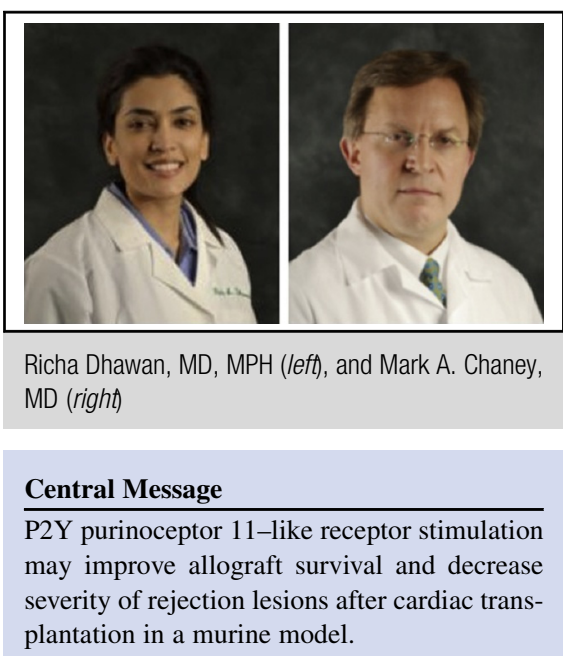

See Article page 780

function of P2Y11 may lie in the use of tissue from animal species that have human P2RY11 orthologs, such as canines and some frog species.

After decades of research on preconditioning, there are no proven methods or pharmacologic interventions for prevention of primary graft dysfunction after cardiac transplantation. Experimental animal studies are conducted in the absence of concomitant disease burden. Thus, translation of animal data to human patients is fraught with the added complexity of comorbid disease and likely alterations in cellular signaling affecting the IR pathway. Regardless of these limitations, animal models remain imperative in elucidating the signals that lead to therapy in human patients. Although we certainly still have a long way to go regarding full knowledge of IR injury, the results of Bourguignon and colleagues ${ }^{1}$ suggest a novel cardioprotective role of P2Y11R in the setting of cardiac transplantation. P2Y11-like receptor stimulation may protect against IR injuries, improve allograft survival, and decrease rejection lesions. Therapeutic interventions that use pharmacologic conditioning with such agonists may improve outcomes after cardiac transplantation.

\section{References}

1. Bourguignon T, Benoist L, Chadet S, Miquelestorena-Standley E, Fromont G, Ivanes F, et al. Stimulation of murine P2Y11-like purinoreceptor protects against hypoxia/reoxygenation injury and decreases heart graft rejection lesions. J Thorac Cardiovasc Surg. 2019;158:780-90.e1.

2. Boeynaems JM, Robaye B, Janssens R, Suarez-Huerta N, Communi D. Overview of P2Y receptors as therapeutic targets. Drug Dev Res. 2001;52:187-9.

3. Dreisig K, Kornum BR. A critical look at the function of the P2Y11 receptor Purinergic Signal. 2016;12:427-37. 